\title{
Closed Pleural Biopsy is Still Useful in the Evaluation of Malignant Pleural Effusion
}

\section{Somnath Bhattacharya, Tapan D Bairagya1, Anirban Das², Abhijit Mandal³, Sibes K Das ${ }^{2}$}

Department of Respiratory Medicine, R.G. Kar Medical College, Kolkata ${ }^{1}$ North Bengal Medical College, Darjeeling, ${ }^{2}$ Medical College, Kolkata, ${ }^{3}$ Bankura Sammilani Medical College, Bankura, West Bengal, India

Address for correspondence: Dr. Sibes Kumar Das, E-mail: sibesdas67@gmail.com

\section{ABSTRACT}

Background: Pleural fluid cytology for malignant cells is the easiest way to diagnose malignant pleural effusion with good sensitivity and specificity. With the introduction of medical thoracoscopy, the use of closed pleural biopsy for the diagnosis of cytology negative malignant pleural effusion is gradually decreasing. However use of thoracoscopy is limited due to its high cost and procedure related complications.

Aims: The aim was to assess the usefulness of closed pleural biopsy in the diagnosis of malignant pleural effusion.

Materials and Methods: Sixty-six patients of pleural effusion associated with malignancy were selected from the patients admitted in the chest ward of a tertiary care hospital over a period of 1 year. Pleural fluid aspiration for cytology and closed pleural biopsy were done in all the patients.

Results: Out of 66 patients, $46(69 \%)$ patients showed malignant cells in pleural fluid cytology examination. Cytology was positive in $35(52 \%), 10(15 \%)$, and $1(1.5 \%)$ patients in the first, second, and third samples respectively. Closed pleural biopsy was positive in 32 (48\%) patients. Among them, 22 also had positive cytology. Additional 10 cytology negative patients were diagnosed by pleural biopsy. Cytology-histology concordance was seen in 12 patients. Definite histological diagnosis could be achieved in five patients with indeterminate cytology. Pleural biopsy was not associated with any major postoperative complication.

Conclusion: Closed pleural biopsy can improve the diagnostic ability in cytology negative malignant pleural effusion. Closed pleural biopsy has still a place in evaluation of malignant pleural effusion especially in a resource-limited country like India.

Key words: Closed pleural biopsy, malignant pleural effusion, pleural fluid cytology

\section{INTRODUCTION}

alignant pleural effusion is a common clinical problem in patients with neoplastic disease. A malignant pleural effusion is diagnosed by detecting exfoliated malignant cells in pleural fluid or demonstrating these cells in pleural tissue obtained by percutaneous pleural biopsy, thoracoscopy or thoracotomy. Pleural effusion associated with

\begin{tabular}{|l|l|}
\hline \multicolumn{2}{|c|}{ Access this article online } \\
\hline Quick Response Code: & Website: \\
\hline & www.jponline.org \\
\hline & \\
\hline
\end{tabular}

malignancy in which there is no direct pleural involvement of the tumor and no other cause of effusion is found called para-malignant effusion. ${ }^{[1]}$

The simplest and minimally invasive way to establish the diagnosis of pleural malignancy is with pleural fluid cytology. Thoracoscopy is the investigation of choice in pleural effusions where a diagnostic pleural aspiration is inconclusive. ${ }^{[2]}$ However, thoracoscopy has several limitations. It is a costly investigation and requires expertise for performance. It also requires backup of thoracic surgery. Obviously it cannot be performed routinely in a resource-poor country like India. Closed pleural biopsy is less sensitive than pleural fluid cytology or thoracoscopy in evaluation of malignant pleural effusions. However it can be easily performed with minimal procedure-related 
complication. Moreover about $7--12 \%$ of patients with malignant pleural effusion can be diagnosed by pleural biopsy when cytology is negative..$^{[3]}$ So closed pleural biopsy is frequently advised in pleural effusions where cytology is negative. ${ }^{[4]}$

Our study was to evaluate the role of closed pleural biopsy in patients with malignant pleural effusions in a tertiary care centre where facilities for thoracoscopy are not available.

\section{MATERIALS AND METHODS}

A total of 66 cases with pleural effusions associated with malignancy admitted in the chest inpatient department of a tertiary care hospital between June 2007 and May 2008 were selected for the study. Inclusion criteria were (a) age more than 18 years, (b) radiological evidence of pleural effusion, (c) evidence of malignancy in pleural fluid cytology or closed pleural biopsy, or cytological/histological evidence of malignancy in an extra-pleural site without evidence of malignancy in pleural fluid cytology or pleural biopsy. Patients with chronic renal failure, bleeding diathesis, and anticoagulant therapy were excluded from the study. All patients were initially evaluated with detailed history, clinical examination, chest radiograph, and CT scan of thorax. Fifty milliliters of pleural fluid was sent for cytological examination. The fluid was stained with Papanicolaou stain and hematoxylin eosin stain and the stained smear was examined for the presence of malignant cell and type of malignancy. If the initial specimen was negative for malignant cell, the cytology was repeated. If the second sample was also negative, a third sample was examined for malignant cell. If all samples were negative, pleural fluid was considered negative for malignant cell. Closed pleural biopsy was done using Abram's pleural biopsy needle under local anesthesia and four samples were obtained from each patient. The patients were observed for any postoperative complication. The sample was sent in a formalin solution for histopathological examination. If both cytology and histopathology were negative for malignancy, malignant etiology of the case was proved with any of the following procedures: biopsy of peripheral lymph node, CT-guided fine-needle aspiration cytology (FNAC) of thoracic mass, fibreoptic bronchoscopic biopsy or ultrasonography-guided FNAC of hepatic metastasis. Written informed consent was obtained from each patient. Ethics committee approval was obtained before the study.

\section{RESULTS}

Sixty-six patients with pleural effusions associated with malignancy were selected. There were 35 (53.5\%) males and $31(46.5 \%)$ females with age range between 28 and 74 years (mean 52.3 years).

Chest X-ray showed massive pleural effusion in $14(21 \%)$ cases, concomitant mass lesions in $12(18 \%)$ cases, collapse in $12(18 \%)$, and mediastinal lymphadenopathy in $6(9 \%)$ cases. CT scan of thorax revealed mass lesion in 26 cases $(39 \%)$, collapse in 13 cases $(20 \%)$, and mediastinal lymphadenopathy in $19(29 \%)$ cases.

Pleural fluid for malignant cells was positive in $46(69 \%)$ cases. The first sample was positive in 35 patients (53\%), second sample was positive in 10 patients $(15 \%)$, but the third sample was positive only in $1(1.5 \%)$ patient. Pleural fluid cytology was negative for malignant cell in 20 (31\%) cases. Closed pleural biopsy showed malignant histology in $32(48 \%)$ cases and was negative in $34(52 \%)$ cases. The results of pleural fluid cytology and pleural biopsy are shown in Table 1.

Out of the 46 cases where cytology was positive, the nature of malignancy could be ascertained in 34 patients. Adenocarcinoma was the most common cytological diagnosis. Table 2 shows the specific cytological type in cytology positive samples.

Adenocarcinoma was also the most common type of malignancy $(65 \%)$ on the basis of analysis of histopathological examination of pleural biopsy sample. Other histological types were squamous cell carcinoma $(3 \%)$, small cell carcinoma ( $6 \%)$, large cell carcinoma (3\%), and indeterminate $(23 \%)$.

There were 22 cases where both pleural fluid cytology and pleural biopsy were positive. Cytological-pathological concordance of these cases are as follows: (a) cytology and histology same in $12(55 \%$ ) cases, (b) cytology inconclusive

\begin{tabular}{|c|c|c|c|}
\hline Cytology & Biopsy & Number & $\%$ \\
\hline Positive & Positive & 22 & 33 \\
\hline Positive & Negative & 24 & 37 \\
\hline Negative & Positive & 10 & 15 \\
\hline Negative & Negative & 10 & 15 \\
\hline
\end{tabular}

\begin{tabular}{lcc}
\hline $\begin{array}{l}\text { Table 2: Types of malignancy on basis of } \\
\text { cytological study }(\mathbf{n}=\mathbf{4 6})\end{array}$ & Number & Percentage \\
\hline \multicolumn{1}{l}{ Type } & 25 & 54 \\
\hline Adenocarcinoma & 4 & 9 \\
Squamous cell carcinoma & 5 & 11 \\
Small cell carcinoma & 12 & 26 \\
Indeterminate & & \\
\hline
\end{tabular}

Journal of Laboratory Physicians / Jan-Jun 2012 / Vol-4 / Issue-1 
but histology diagnostic in 5(23\%)cases, (c) cytology diagnostic but histology inconclusive in $3(13 \%)$ cases, and (d) cytology and histology giving different diagnosis in $2(9 \%)$ cases.

All the five cases in which cytology was inconclusive, but biopsy yielded definite results were adenocarcinoma. Among the three cases where cytology was conclusive but biopsy could not ascertain the type, two were adenocarcinoma and one squamous cell carcinoma. In the two cases with cytological--histological nonconcordance, the cytological diagnosis was squamous cell carcinoma but the pleural biopsy revealed adenocarcinoma. In the 10 patients where both cytology and histopathology were negative, the presence of malignancy was ascertained by excision biopsy of lymph nodes $(n=5)$, FNAC of lung mass under CT guidance $(n=3)$, USG-guided FNAC from hepatic metastasis $(n=1)$ and fibreoptic bronchoscopy $(n=1)$.

\section{DISCUSSION}

The diagnostic yield of pleural fluid cytology has shown a wide variation ranging from $40 \%$ to $90 \% .^{[5-8]}$ Several factors influence the yield including mechanism of effusion, type of primary tumor, nature of specimens, number of specimens and the skill of the cyto-pathologists. Para-malignant effusions will obviously have fewer yields than the malignant effusions. Among the primary tumors diagnostic rate is higher in adenocarcinoma than in mesothelioma, squamous cell carcinoma, lymphoma, and sarcoma. ${ }^{[2,9]}$ If both cell blocks (formed by centrifuging the sample and extracting the solid cellular portion) and smears are prepared the yield becomes better than if only one method is used. ${ }^{[10,11]}$ The yield from sending more than two samples is low. One study found the yield of $65 \%, 27 \%$, and $5 \%$ from the first, second, and third samples respectively. ${ }^{[8]}$ Moreover, there is still controversy regarding the optimal amount of fluid to be submitted for examination. While one recent study showed that $60 \mathrm{~mL}$ of fluid produced better sensitivity than $10 \mathrm{~mL},{ }^{[12]}$ another previous study showed that sending fluid more than $50 \mathrm{~mL}$ did not improve the diagnostic yield. ${ }^{[13]}$ Our study has confirmed the influence of almost all the factors in diagnostic yield. In our study the overall diagnostic yield was $70 \%$, adenocarcinoma was the most common diagnosis (54\%) and the yield in the third fluid sample was significantly lower $(1.5 \%)$ than the first and second samples (53\% and 15\% respectively). We used both cell blocks and smears to increase the yield and submitted $50 \mathrm{~mL}$ of fluid in each patient to avoid the controversy of optimum amount of fluid.
When pleural fluid cytology is negative in a suspected case of malignant pleural effusion, there are several options for further investigations like image-guided cutting needle biopsy, closed pleural biopsy, medical thoracoscopy, video-assisted thoracic surgery, and thoracotomy. In malignant pleural effusions, closed pleural biopsies are less sensitive than pleural fluid cytology. A review of pleural biopsy yield from 2893 examinations show a diagnostic yield of only $57 \%$ for malignancy. ${ }^{[14]}$ However the yield ranged from $40 \%$ to $75 \% \cdot{ }^{[15-19]}$ The relatively low yield of blind pleural biopsy is due to scarce, patchy and irregular distribution of the tumor invasion of the pleura. However studies have shown that $7 \%$ to $12 \%$ of patients with malignant effusions may be diagnosed by pleural biopsy when cytology is negative. ${ }^{[3,15,20]}$ Contrast-enhanced thoracic CT scan will often show a focal area of abnormal pleura which can be biopsied with an image guided cutting needle biopsy. It has a higher diagnostic yield than that of blind pleural biopsy in diagnosis of malignant effusions. In a study the sensitivity of blind biopsy and cutting needle biopsy to diagnose malignancy was $47 \%$ and $87 \%$ respectively. ${ }^{[21]}$ This method can be particularly useful in patients who are unsuitable for thoracoscopy. Medical thoracoscopy is suggested as investigation of choice in cytology negative patients. But thoracoscopy is not available in most centers, is a costly procedure, has about $2.3 \%$ incidence of major complications, and needs hospitalization and thoracic surgery backup. Thoracoscopy may also yield false negative results due to insufficient or nonrepresentative biopsy or presence of adhesions that prevent access to neoplastic tissue. ${ }^{[22,23]}$ It is opined that discouragement of closed pleural biopsy by western literature unfortunately translated into its decline in India. ${ }^{[24]}$ Blind pleural biopsy is easily available, can be done on an outpatient basis, and has minimal complications in an experienced hand. It is a useful procedure specially when thoracoscopy is unavailable or the patient is too sick to tolerate thoracoscopy. Moreover it is highly sensitive and cost-effective test to exclude unsuspected tuberculosis in a resource-poor country with a high incidence of tuberculosis. So there is necessity to redeem the practice of closed pleural biopsy among pulmonologists through proper awareness and encouragement. ${ }^{[24]}$

\section{CONCLUSION}

Closed pleural biopsy can aid in the diagnosis of malignant pleural effusion. It can also give the definite histological diagnosis in patients with indeterminate cytology. It is also a cost-effective and safe procedure. It is still highly relevant especially in a resource-limited country like ours 
where thoracoscopy is available only in few tertiary care centers of large cities.

\section{ACKNOWLEDGEMENT}

We acknowledge Dr Goutam Kumar Sain, consultant pathologist, ESI Hospital, Belur for his contribution in cytological and histopathological procedures.

\section{REFERENCES}

1. Sahn SA. Malignant pleural effusions. In: Fishman AP, Elias JA, Fishman JA, Grippi MA, Senior RM, Pack AI, editors. Fishman's Pulmonary Diseases and Disorders. Vol. 2. $4^{\text {th }}$ ed. New York: McGraw Hill Medical; 2008. p. 1505-15.

2. Hooper C, Lee YCG, Maskell N. Investigation of a unilateral pleural effusion in adults: British Thoracic Society pleural disease guideline 2010. Thorax 2010;65:ii4-17.

3. Loddenkemper R, Grosser H, Gabler A, Mai J, Preussler H, Brandt HJ. Prospective evaluation of biopsy methods in the diagnosis of malignant pleural effusions: Intrapatient comparison between pleural fluid cytology, blind needle biopsy and thoracoscopy. Am Rev Respir Dis 1983;127 (Suppl 4):114.

4. Villena V, Lopez Encuentra A, Echave - Sustaeta J, Alvarez Martinez C, Martin Escribano P. Prospective study of 1000 consecutive patients with pleural effusion. Etiology of the effusion and characteristics of the patients. Arch Bronconeumol 2002;38:21-6.

5. Salyer WR, Eggleston JC, Erozan YS. Efficacy of pleural needle biopsy and pleural fluid cytopathology in the diagnosis of malignant neoplasm involving the pleura. Chest 1975;67:536-9.

6. Light RW, Erozan YS, Ball WC. Cells in pleural fluid. Their value in differential diagnosis. Arch Intern Med 1973;132:854-60.

7. Sahn SA. Pleural diagnostic techniques. Curr Opin Pulm Med 1995;1:324-30.

8. Garcia LW, Ducatman BS, Wang HH. The value of multiple fluid specimens in the cytological diagnosis of malignancy. Mod Pathol 1994;7:665-8.

9. Melamed MR. The cytological preparation of malignant lymphomas and related diseases in effusions. Cancer 1963;16:413-31.

10. Fetsch PA, Abati A. Immunocytochemistry in effusion cytology: A complementary review. Cancer 2001;93:293-308.
11. Dekker A, Bupp PA. Cytology of serous effusions: An investigation into the usefulness of cell blocks versus smears. Am J Clin Pathol 1978;70:855-60.

12. Swiderek J, Morcos S, Donthireddy V, Surapaneni R, Jackson - Thompson V, Schultz L, et al. Prospective study to determine the value of pleural fluid required to diagnose malignancy. Chest 2010;137:68-73.

13. Abouzgheib W, Bartter T, Dagher H, Pratter M, Klump W. A prospective study of the volume of pleural fluid required for accurate diagnosis of malignant pleural effusion. Chest 2009;135:999-1001.

14. Tomlinson JR. Invasive procedures in the diagnosis of pleural disease. Semin Respir Med 1987;9:30-60.

15. Prakash UBS, Reiman HM. Comparison of needle biopsy with cytologic analysis for the evaluation of pleural effusion: Analysis of 414 cases. Mayo Clin Proc 1985;60:158-64.

16. Starr RL, Sherman ME. The value of multiple preparations in the diagnosis of malignant pleural effusions. A cost-benefit analysis. Acta Cytol 1991;35:533-7.

17. Kumar ND, Bhatia A, Mishra K, Suri JC. Comparison of pleural fluid cytology and pleural biopsy in the evaluation of pleural effusion. J Indian Med Assoc 1995;93:307-9.

18. Poe RH, Israel RH, Utell MJ, Hall WJ, Greenblatt DW, Kalley MC. Sensitivity, specificity, and predictive values of closed pleural biopsy. Arch Intern Med 1984;144:325-8.

19. Escudero BC, Garcia CM, Cuesta CB, Molinos ML, Rodriguez RS, Gonzalez PA, et al. Cytologic and bacteriologic analysis of fluid and pleural biopsy specimens with Cope's needle. Study of 414 patients. Arch Intern Med 1990;150:1190-4.

20. Nance KV, Shermer RW, Askin FB. Diagnostic efficacy of pleural biopsy as compared with that of pleural fluid examination. Mod Pathol 1991;4:320-4.

21. Maskell NA, Gleeson FV, Davies RJ. Standard pleural biopsy versus CT-guided cutting-needle biopsy for diagnosis of malignant disease in pleural effusions: A randomized controlled trial. Lancet 2003;361:1326-30.

22. Loddenkemper R, Boutin C. Thoracoscopy: Present diagnostic and therapeutic indications. Eur Respir J 1993;6:1544-55.

23. Boutin C, Viallat JR, Cargnino P, Farisse P. Thoracoscopy in malignant pleural effusions. Am Rev Respir Dis 1981;124:588-92.

24. Dutt N, Agarwal D. Closed pleural biopsy: A victim of western advancement? Lung India 2011;28:322.

How to cite this article: Bhattacharya S, Bairagya TD, Das A, Mandal A, Das SK. Closed pleural biopsy is still useful in the evaluation of malignant pleural effusion. J Lab Physicians 2012;4:35-8.

Source of Support: Nil. Conflict of Interest: None declared.

\section{Dispatch and return notification by E-mail}

The journal now sends email notification to its members on dispatch of a print issue. The notification is sent to those members who have provided their email address to the association/journal office. The email alerts you about an outdated address and return of issue due to incomplete/incorrect address.

If you wish to receive such email notification, please send your email along with the membership number and full mailing address to the editorial office by email. 